\section{Kompass \\ Ophthalmologie}

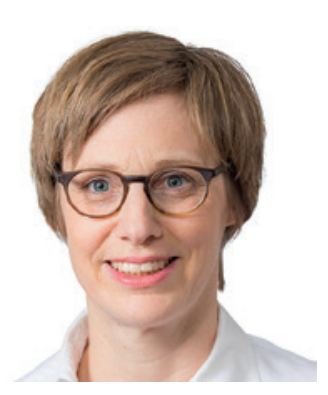

\title{
Eye injuries due to private fireworks and firecrackers
}

\section{Ameli Gabel-Pfisterer ${ }^{a}$ Daniel Böhringer ${ }^{b}$ Hansjuergen Agostini ${ }^{b}$}

a Augenklinik, Klinikum Ernst-von-Bergmann, Potsdam, Germany; ${ }^{b}$ Klinik für Augenheilkunde, Medizinische Fakultät, Universitätsklinikum Freiburg, Freiburg im Breisgau, Germany

Abstract of Gabel-Pfisterer A, Böhringer D, Agostini H: 3-year results of the German nationwide survey on eye injuries caused by fireworks. Ophthalmologe 2019;116, 1138-1151.

\section{Keywords}

Fireworks · Wounds and injuries · Eye · Explosives · Register study

\footnotetext{
Abstract

Background: On festive days worldwide eyes are severely injured by fireworks. The data on the number and severity are to date not registered in Germany.

Objective: How frequent are firework-induced injuries in Germany, who are the affected, how serious are the injuries, which forms of treatment are necessary and how frequent are accompanying injuries?

Method: A German nationwide online-based survey was carried out in all inpatient eye departments and data over the last 3 consecutive years were descriptively analyzed.
}

Results: From New Years Eve 2016/2017, when 41 eye departments sent in data, the participation could be increased to 51 eye departments in 2018/2019. More than one third (33-39\%) of all 1356 patients over 3 years were minors, $60 \%$ were younger than 25 years old and roughly $60 \%$ of patients were injured as bystanders or in an unclear situation. In total $25 \%$ of all eye injuries were considered severe and required inpatient treatment. Accompanying injuries of the other eye, the face and hands were more frequent in minors than in adults. Eyeball ruptures were reported in 10 minors and 38 adults over the 3 years.

Summary: Particularly minors and bystanders need better protection.

C 2019 The Author(s) 


\section{Knowledge transfer}

\section{Background}

On the morning of New Year's day, the boy finds firecrackers that have been left lying around, lights them, and injures his left eye and right hand so badly that his plans to become a carpenter are blasted away. This is how we as ophthalmologists all too often experience the turn of the year.

Some of the eye injuries caused by pyrotechnic articles are uncomplicated, affect the eyelids or the surface of the eye and, provided that no scars are left, have a relatively good prognosis. In a considerable number of cases, however, a combination of mechanical, chemical and thermal effects causes severe surface injuries, blunt eye contusions or tearing of the eyeball, which despite intensive therapy leave permanent damage after healing. These injuries are particularly dramatic when children, young people and uninvolved onlookers or passers-by are affected.

In Germany, in contrast to the USA, so far there has been no systematic recording of the causes of eye injuries.

In order to learn more about the frequency and severity of these eye injuries caused by pyrotechnic articles in Germany, since the turn of 2016/2017 the DOG (Deutsche Ophthalmologische Gesellschaft, German Ophthalmological Society) has been conducting a prospective, anonymous online survey on eye injuries caused by fireworks at all emergency eye clinics throughout the country. This survey is intended to find out which groups of people are particularly at risk in which situations, and which kinds of pyrotechnic articles are causally involved. Furthermore we record the frequency and severity of injuries, the necessary therapies, and the occurrence of concomitant injuries. So far, the 3-year data have been published [1].

\section{Four-year data: Children and adolescents overrepresented among the injured}

At the annual conference 2020 we will present the 4-year data, which are consistent across all the turns of the years: From 1878 evaluated data sets, we can see that children and adolescents account for about 39\% of those affected, while as of December 2019 they constitute only $16.5 \%$ of the total population. Their portion among the injured people has even tended to increase slightly over the years (2016/17: 33\%, 2017/18: 39\%, 2018/19: 37\%, and 2019/20: 40\%). Children and adolescents are injured mainly by cannon crackers (aka. bangers), while among adults, injuries from rockets dominate.

\section{Onlookers and passers-by are affected in about half of the cases}

What we find particularly alarming: The proportion of injured persons who claim not to have lighted the firecracker themselves, or to have been hit in an unclear situation, is $50-60 \%$ throughout the years, depending on the age group.

Around a quarter of all patients suffer serious injury and require inpatient treatment. Diagnosis of these complex injuries, in many cases characterised by combinations of thermal, mechanical and chemical effects, can be difficult. According to the primary examiners of our study, $30-40 \%$ of the patients enrolled in the study require further treatment after initial inpatient care.

We have documented severe tearing of the eyeball in 54 patients.

\section{Concomitant injuries}

Throughout the 4 years, bilateral eye injuries caused by fireworks were recorded in more than 15\% of the patients on average. Almost a quarter of the children and a third of the adults affected suffer not only ocular but also facial injuries that may lead to functional and cosmetic limitations. We recorded additional injuries to the hands in $17 \%$ of the children and adolescents.

\section{Often severe long-term consequences despite maximum therapy}

Various studies show the limited long-term results in terms of vision despite intensive therapy. An evaluation of 200 patients treated at the Ophthalmologic University Hospital in Leipzig after such injuries showed that almost $40 \%$ of the patients with severe eye injuries had a mean visual acuity of only $20 \%$ at the end of the follow-up period [2].

\section{Socio-economic consequences of eye injuries from fireworks} Apart from individual pain and long-term visual impairment, eye injuries caused by fireworks have other socio-economic consequences in addition to the direct treatment costs, as a study by the Ophthalmologic University Hospital Halle shows. Almost a third of all the 144 patients treated there during the last 12 years with eye injuries caused by fireworks required in-patient treatment, which resulted in an average of 24 days of incapacity for work [3].

\section{Successful prevention is possible}

Various publications from the Netherlands and Finland over the past one and a half decades show how the frequency and severity of fireworks injuries have changed upon introduction of legislative amendments. In the Netherlands, for example, at the turn of the year 2016/2017, a shortening of the times during which private fireworks may be lighted led to a halving of the number of people injured. In Finland, a ban on cannon crackers has led to reduction in concomitant hand injuries in children and adolescents to almost zero. In either country, the legislative change was largely triggered by the activity of the study authors. Thus they support one of the objectives of the International Council of Ophthalmology (ICO) and the European Society of Ophthalmologists (SOE): a cross-border ban on private fireworks [4].

To raise awareness of the risks of private fireworks in Germany, the DOG has published a poster based on the results of our survey. We hope that it will be posted and read in many ophthalmologic and paediatric practices, as well as in schools and kindergartens. 
What further measures are expedient, e.g. to make it more difficult for children and adolescents to have access to category-2 fireworks, which are already prohibited but apparently not very strictly controlled? It is to be doubted that information alone suffices. A ban on the sale of cannon crackers could, as a first step, reduce the risk of injury not only to the eyes but also to the hands of children.

And how can onlookers and passers-by be protected more effectively under the laws currently in force?

What can we do to influence legislation so that the frequency of dramatic and serious injuries is reduced in the long term? We will continue the survey at the German eye clinics in the future as well, in order to record long-term changes in frequency, usage behaviour and injury patterns. In the future we want to see fewer of these avoidable and all too often dramatic injuries, preferably NONE AT ALL!

If fireworks are to be lighted, let them be safe fireworks!

\section{Disclosure Statement}

The authors state that there is no conflict of interest.

\section{References}

1 Gabel-Pfisterer A, Böhringer D, Agostini H: Dreijahresergebnisse der deutschlandweiten Umfrage zu Augenverletzungen durch Feuerwerkskörper. Ophthalmologe 2019;116, 1138-1151.

2 Unterlauft JD, Rehak M, Wiedemann P, et al.: Firework-related eye trauma in Germany. Curr Eye Res. 2018;43(12):1522-1528.

3 Huth A, Löffler L, Viestenz A: Feuerwerksverletzungen am Auge in den letzten 11 Jahren. Eine Auswertung der Universitätsklinik und Poliklinik für Augenheilkunde Halle. Ophthalmologe 2019;116:1171-1176.

4 de Faber JT, Kivelä TT, Gabel-Pfisterer A: Landesweite Studien aus den Niederlanden und Finnland zur Häufigkeit von Augenverletzungen durch Feuerwerkskörper unter dem Einfluss verschiedener Schutzmaßnahmen. Ophthalmologe 2019;116:1177-1183.

Correspondence: Dr. Ameli Gabel-Pfisterer, Augenklinik, Klinikum Ernst von-Bergmann, Charlottenstraße 72, 14467 Potsdam, Germany, ameli. gabel-pfisterer@klinikumevb.de 